\title{
ALWAYS: a plot-based silvopastoral system model
}

\author{
Jacques-Eric Bergez $^{\mathrm{a}, *}$, Michel Etienne ${ }^{\mathrm{b}}$, Philippe Balandier ${ }^{\mathrm{c}}$ \\ a MLURI, Land-Use Science Group, Aberdeen AB15 8QH, UK \\ ${ }^{\mathrm{b}}$ INRA, Unité d'Ecodéveloppement, domaine de St Paul, Site Agroparc, 84914 Avignon, France \\ ' CEMAGREF, Division Foret et Agroforesterie, 24, av. des Landais, BP 50085, 63172 Aubière cedex, France
}

Received 23 May 1997; accepted 19 August 1998

\begin{abstract}
Accounting for interactions is an important feature in ecological modelling when dealing with complex systems. ALWAYS is an object-oriented model which describes the biophysical functioning of a silvopastoral system at a plot and daily scale. The main processes linking the five components of the system (climate, tree, sward, soil and animal) are described. The interactions processes between the different components of the system are taken into account and resources sharing is modelled. The main biophysical equations are developed (tree and sward growth, water cycle, transmitted PAR). ALWAYS offers three ways of running it: (i) interactively by running the simulation year by year and checking results at the end of each year using graphs and output files; (ii) automatically by describing the management over the full tree rotation and (iii) in a sensitivity analysis mode to test parameters from the yearly or rotation outputs. Examples of output files, written in an ASCII format, are provided. Such a model is the first step towards a more effective decision support tool. (C) 1999 Elsevier Science B.V. All rights reserved.
\end{abstract}

Keywords: Silvopastoral system; Object modelling; DSS; Biological interactions; Ecological processes

\section{Introduction}

Over the past 10 years, agricultural policy in Europe has changed progressively. It has shifted from price support policies towards more environmentally friendly policies with greater emphasis

\footnotetext{
* Corresponding author. Present address: INRA, Station d'agronomie, BP 27, 31326 Castanet Tolosan Cedex, France; Tel.: +33-5-61285037; Fax: + 33-5-61735537; e-mail: jbergez@toulouse.inra.fr.
}

being given to the aspects of land quality and sustainability. Production from such policies is quite often based on the use of mixed production systems on the same land area (Guitton, 1994; Guitton et al., 1994). Decision support models based on single enterprises, for example, crops or animals, need to be reassessed within a new general view. Interactions, often excluded from single enterprise models, have now to be taken into account enabling further research needs to be 
stressed in some areas where knowledge is weak as far as complex biological systems are concerned (Anderson and Sinclair, 1993).

A silvopastoral system is an agricultural system where, on the same unit of land, trees, pasture and animals coexist. Trees and sward compete for water, nutrients and light resources. Water constraint may be more important (competition for water) or less important (decrease of the potential evapo-transpiration under the trees) in such a system. Trees create shelter and forage for the animals. Animals may modify tree growth by browsing, rubbing, soil compaction or by dung and urine return. This is an example of a complex biological system in terms of multiple interactions (Sibbald, 1996). A large number of silvopastoral systems can be found in Europe. They are present in very contrasted land-use systems, and are adapted to specific pedo-climatic and land tenure conditions (Etienne, 1996).

Silvopastoral systems combine long-term production (timber and fuel-wood) with annual production (forage and meat). These systems involve interactions between the different components in terms of space occupation (vertical and horizontal stratification; above and below-ground) and resource allocation (light, water, nutrients) (Anderson and Sinclair, 1993). The key part of such a system is the tree-sward-animal association. Describing the interactions between these components over time is crucial to the understanding of the evolutionary production of the system. Two types of interaction may be defined.

- Direct interaction: a biotic component interacts directly with another biotic component (e.g. an animal browsing a tree).

- Indirect interaction: a biotic component modifies an abiotic component used by another biotic component (e.g. light reduction for sward photosynthesis resulting from shading by the tree canopy; increase of nitrogen available for sward production by returns of animal dung and urine).

Although many models exist for the simulation of crop or animal growth or of pesticide or nutrient transport (Thornley and Verberne, 1989), little attention has been paid to the development of models accounting for multiple enterprise systems such as silvopastoral ones. The few models available usually focus only on a particular interaction or on a specific process. They also focus mainly at a particular or habitat scale and, as they are often developed by ecologists, they rarely consider the farmer as part of the system. Following Muetzelfeldt and Sinclair (1993) we can consider descriptive, prescriptive and predictive models. The descriptive model provides a precise description of some properties of the system such as its architecture (Oldeman, 1992; De Reffye et al., 1995) or its carbon or energy budget (McMurtrie and Wolf, 1983; González, 1984). The prescriptive model generates management recommendations according to land allocation optimisation (Maxwell et al., 1979), risk aversion (Lilieholm and Reeves, 1991) or economic criteria (Garcia-de-Ceca and Gebremedhin, 1991). These models are generally based on linear inter-relationships between tree cover, forage and/or animal production (Uresk and Sevenson, 1989; Mitchell and Bartling, 1991; Scanlan, 1992; Khan and Pathak, 1995). The predictive model predicts system behaviour and the consequences of management actions. It models interactions such as radiation interception (Giordano et al., 1986; Kuuluvainen and Pukkala, 1989; Reid and Ferguson, 1992) and sometimes deals with the effect of these interactions on production. In this case, the model integrates several climatic and edaphic factors and provides physical (McKeon et al., 1990; Sibbald et al., 1990; Msika, 1993) or economic outputs (Doyle et al., 1986).

The model presented below is called ALWAYS ('Alternative Land-use With AgroforestrY Systems) and is the result of a European Commission contract (AIR3 CT-92-0134) (Auclair, 1996). This contract was initiated in 1993 by 18 research and development institutes from six European countries, with the financial help of the European Commission. Its general objective was to contribute to the diversification of intensive uses of agricultural land with the help of fast growing broad-leaved high quality trees. It was more specifically concerned with the development of a silvopastoral modelling system, taking into account the technical aspects and integrating biophysical and economic data, devoted to simulation and decision-making for farmers, landowners, and land-managers. 
The aim of this paper is to show how a silvopastoral system can be modelled taking into account the interaction processes between the different parts of the system and integrating the plot management practices.

\subsection{Specifications of the ALWAYS model}

ALWAYS is a plot-based model simulating the temporal biophysical behaviour of a silvopastoral system taking into account the interactions between the different components of such a system. In this respect, it is a predictive model. It allows testing of new land-use systems based upon fast growing broad-leaved, high quality timber production from set-aside farmland, inside an agricultural system. As such, it is a prescriptive model. It was decided to develop:

- a plot-based model because it does not attempt to deal with the complexity of the farm as a whole, but is framed by the physical boundary of a rectangular, homogeneous plot (in terms of soil and climate);

- a biophysical model because it uses the climate and the soil to drive the growth of the biological components of the system;

- a silvopastoral model because it deals with pasture, planted trees and animals (sheep), and not with established forest (forest grazing) or crops.

Several users were targeted:

- Scientists: to be able to test processes and interactions between components of such a biological system; to identify gaps in knowledge and to underline new areas of research; to develop preferential and considered management rules.

- Student-teachers: to show how such a biological system may work;

- Agriculture advisors: to demonstrate what a silvopastoral system is and how it works; to help establish demonstration plots by giving some ideas on production variation over time. As far as modelling is concerned, an abstraction of reality is required to allow a simplification of the processes. This may be achieved by a careful description of the system and of the interactions involved. In a silvopastoral plot (Fig. 1), five main components may be identified: the climate, the soil, the trees, the sward and the animals. The climate and the soil may be considered as abiotic components (microbial processes in the soil are not considered) while the other three may be seen as biotic components. The two abiotic components are mainly the medium in which the biotic components seek to fulfil their requirements in terms of energy, water and nutrients and the space to capture them. The climate is driven by stochastic events, while the soil is based on an input/output driven process. Both climate and soil

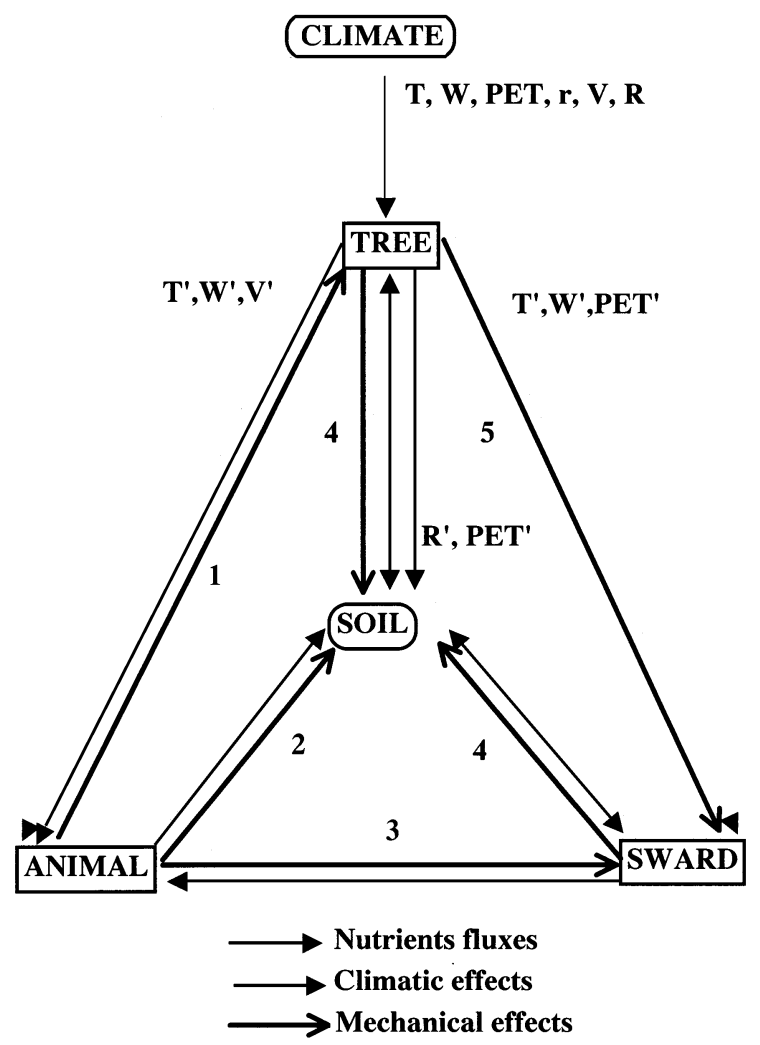

Fig. 1. Schematic representation of a silvopastoral system. Two mediums (round boxes) and three biological units (square boxes) interact and exchange information either as nutrient fluxes (solid arrow), climatic effects (dashed arrow) or mechanical effects (bold arrow), the later being mainly: 1, browsing and rubbing; 2, compaction; 3, grazing pressure; 4, modification of the soil structure; 5, mulching. The climatic variables are temperature $(T)$, radiation $(W)$, potential evapo-transpiration (PET) relative humidity $(r)$, wind $(V)$ and rainfall $(R)$. The modified climatic variables are shown with '. 
are involved in the interaction processes by generating resources to be shared by the biotic components.

Since 1990, object-oriented analysis and objectoriented design (Booch, 1994) has been used successfully to describe biological processes (Sequiera et al., 1991; Silvert, 1993; Acock and Reynolds, 1997). The advantages of such a choice are listed by Sequiera et al. (1997) or Acock and Reddy (1997) and may be summarised as: (i) the modularity of the written code allows easier reusable models; (ii) objects describing entities (e.g. a plant or an animal) or processes (e.g. photosynthesis or maintenance respiration) are closer to the real world and so more easy understood by non-programmer scientists; (iii) there is a similitude between the state variables as described by the modellers and the private attributes of an object as implemented by the programmer; (iv) encapsulation, polymorphism and inheritance allow to create different objects (child objects) from a single object (parent object) with relation between objects like an object $\mathrm{X}$ is an object $\mathrm{Y}$ or an object $\mathrm{X}$ is part of an object $\mathrm{Y}$.

Fig. 1, showing a description of the system and of the interactions, is the basis of the object-oriented analysis of the model. Abiotic and biotic components may be described in terms of objects as defined by object-oriented concepts, i.e. with their own properties, which are exclusively intrinsic to them (quite often these are the state variables) and their methods, which provide knowledge of the state of the object at a given time and allow to modify the properties according to external or internal processes and to read and generate information from/to a core programme. Five main objects are identified within ALWAYS: the Tree, the Sward, the Climate, the Animal and the Soil. Management, which is an important factor when dealing with the many unknowns in such a new system, was not described in terms of objects, but is dealt with the methods of the main objects (e.g. applying fertiliser to the sward, pruning the trees, putting out the flock, harvesting pasture for hay). Interactions are based on the exchange of information between the different objects.

\subsection{Description of the main biophysical equations}

To emphasise the interactions between the different components of a silvopastoral systems, the description of the biophysical functioning will be presented (i) by the incrementation of the state variables (main growth processes) and (ii) by the description of the resource sharing. It is not intended to give all the equations in this paper, but to stress the interaction processes and how resource sharing has been tackled. A more precise description of the theoretical processes involved in the biological functioning of the system may be found in Bergez and Msika (1996). To distinguish between the two different time steps involved in the biophysical equation of our silvopastoral model, we noted $t_{\mathrm{y}}$ the yearly time step and $t$ the daily one.

\subsubsection{Tree growth}

According to Forestry Commission (1980) data and to more recent data for widely spaced trees (Cabanettes et al., 1998), tree height $(H)$ and tree diameter at breast height $(D)$ are described by a mono-molecular function and a Gompertz function, respectively:

$H\left(t_{y}\right)=H_{\mathrm{x}} \cdot\left(1-e^{-k_{\mathrm{t}, \mathrm{d}} \cdot m \cdot t_{\mathrm{y}}}\right)$
$D\left(t_{y}\right)=D_{\mathrm{x}} \cdot e^{-e^{-k_{\mathrm{t}, \mathrm{d}} \cdot B \cdot\left(t_{\mathrm{y}}-M\right)}}$

where $B, m$ and $M$ are tree growth parameters; $H_{\mathrm{x}}$ and $D_{\mathrm{x}}$ are respectively the maximum tree height and the maximum tree diameter; $k_{\mathrm{t}, \mathrm{h}}$ and $k_{\mathrm{t}, \mathrm{d}}$ are random growth parameters describing the genotypic variability; $t_{\mathrm{y}}$ is the time (in year).

To take into account the water constraint on growth, the derivative functions are used:

$$
X\left(t_{\mathrm{y}}+1\right)=X\left(t_{y}\right)+\left[1-f_{\mathrm{t}, \mathrm{w}}\left(t_{y}\right)\right] \cdot g^{\prime}\left[g^{-1}\left(t_{\mathrm{y}}\right)\right]
$$

where $g\left(t_{\mathrm{y}}\right)$ is the growth function [either $H\left(t_{\mathrm{y}}\right)$ or $\left.D\left(t_{\mathrm{y}}\right)\right] ; g^{-1}(X)$ is the inverse function; $g^{\prime}\left(t_{\mathrm{y}}\right)$ is the derivative function; $f_{\mathrm{t}, \mathrm{w}}\left(t_{\mathrm{y}}\right)$ is the growth reduction factor due to water stress during the growing season. It is calculated using the integration of daily water constraints $\left[k_{\mathrm{t}, \mathrm{w}}(t)\right]$ given by:

$k_{\mathrm{t}, \mathrm{w}}(t)=1-\frac{Q_{\mathrm{t}, \mathrm{u}}(t)}{Q_{\mathrm{t}, \mathrm{n}}(t)}$ 
where $Q_{\mathrm{t}, \mathrm{u}}(t)$ is the actual amount of water taken up by the tree; $Q_{\mathrm{t}, \mathrm{n}}(t)$ is the amount of water required by the tree.

\subsubsection{Sward growth}

Two types of model are provided to the user to implement sward growth: a mechanistic model based on the model developed by Thornley and Verberne (1989) and an empirical model based on the model developed by De Montard (1986) and Coppel and Étienne (1992). In the following, we will developed the latter one. Daily net production $\left[\mathrm{d} W_{\mathrm{s}}(t)\right]$ is linked to mean air temperature $\left[T_{\mathrm{m}}(t)\right]$, photosynthetically active radiation $[\operatorname{PAR}(t)]$ and water constraint $\left[k_{\mathrm{s}, \mathrm{w}}(t)\right]$ :

$\mathrm{d} W_{\mathrm{s}}(t)=\alpha \cdot T_{\mathrm{m}}(t)^{a} \cdot \operatorname{PAR}(t)^{b} \cdot k_{\mathrm{s}, \mathrm{w}}(t)^{v}$

where $\alpha, a, b$ and $c$ are sward growth parameters. These parameters vary depending on the species and on the physiological stage of the sward. Growth starts in spring when the accumulated temperature reaches a given threshold.

Water constraint is given by:

$K_{\mathrm{s}, \mathrm{w}}(t)=1-\frac{Q_{\mathrm{s}, \mathrm{u}}(t)}{Q_{s, n}(t)}$

where $Q_{\mathrm{s}, \mathrm{u}}(t)$ is the actual amount of water taken up by the sward; $Q_{\mathrm{s}, \mathrm{n}}(t)$ is the amount of water required by the sward.

Fertilizer application enhances sward growth $\left[\mathrm{d} W_{\mathrm{s}, \mathrm{f}}(t)\right]$ :

$\mathrm{d} W_{\mathrm{s}, \mathrm{f}}(t)=\frac{\mathrm{d} W}{\mathrm{~d} N} \cdot N$

where $\mathrm{d} W / \mathrm{d} N$ is the biomass increment due to an amount of one unit of fertilizer for a given period; $N$ is the amount of applied fertilizer.

Senescence process $\left[\mathrm{d} W_{\mathrm{s}, \mathrm{d}}(t)\right]$ is described by:

$\mathrm{d} W_{\mathrm{s}, \mathrm{d}}(t)=k_{\mathrm{s}, \mathrm{d}} \cdot W_{s}(t)$

where $k_{\mathrm{s}, \mathrm{d}}$ is the rate of mortality depending on temperature and water; $W_{\mathrm{s}}(t)$ is the current sward biomass.

\subsubsection{Animals growth}

Only lambs grow, but the state of the animals may change:

- ewes may become pregnant;
- when pregnant ewes are due, they become lactating ewes and either single or twin lambs born;

- when lactation stops, the ewe become nonpregnant, non-lactating;

- lambs become adult.

Each category of animal runs an internal clock allowing their state to be changed. According to this state, specific animal requirements are calculated (energy and dry matter) and the ability of the pasture quality and quantity to cover these requirements is checked.

Lambs grow linearly:

$W_{1}(t)=W_{1}(t-1)+\mathrm{LGR}$

where LGR is the lamb growth rate.

\subsubsection{Climate}

The model uses a 40 year climatic series of daily data either provided by the user or simulated randomly by the programme from a limited number of selected years (chosen because they are representative) and their frequency of occurrence. The trees modify the general daily climate to a specific daily micro-climate.

1.2.4.1. Photosynthetically active radiation. The mean photosynthetic active radiation on the plot $\left(\mathrm{PAR}_{\mathrm{m}}\right)$ is obtained by averaging direct PAR $\left(\mathrm{PAR}_{0}\right)$ on the uncovered surface and transmitted PAR $\left(\mathrm{PAR}_{\mathrm{t}}\right)$ plus diffuse PAR $\left(\mathrm{PAR}_{\mathrm{d}}\right)$ on the shaded surface, weighed by the area of each surface. A vertical projection of the tree canopy $\left(A_{\mathrm{i}, \mathrm{c}}\right)$ is used to determine the shaded area (Jackson and Palmer, 1979):

$\operatorname{PAR}_{\mathrm{t}}(t)=\operatorname{PAR}_{0}(t) \cdot e^{\left[-0.5 \cdot L_{\mathrm{d}}(t) \cdot s\left(t_{\mathrm{y}}\right)\right]}$

$A_{\mathrm{c}}=\sum_{i=1}^{n} A_{i, \mathrm{c}}\left(t_{\mathrm{y}}\right)$

$\mathrm{PAR}_{\mathrm{m}}$

$=\frac{\left[\operatorname{PAR}_{\mathrm{d}}(t)+\operatorname{PAR}_{\mathrm{t}}(t)\right] \cdot A_{\mathrm{c}}+\operatorname{PAR}_{0}(t) \cdot\left(A_{\mathrm{p}}-A_{\mathrm{c}}\right)}{A_{\mathrm{p}}}$

where $L_{\mathrm{d}}(t)$ is the leaf area density in the tree crown; $s\left(t_{\mathrm{y}}\right)$ is the height of the crown; $A_{\mathrm{p}}$ is the plot area; $\mathrm{n}$ is the number of trees on the plot. 
1.2.4.2. Temperature. In a silvopastoral system, the average temperature is not modified (Sibbald et al., 1990; Msika, 1993) but the minimum air temperature is increased depending on the tree cover and on the leaf area of the trees (Msika, 1993). There are two aspects to be taken into account.

1. The stem during winter time reduces advection: a maximum increase of $1^{\circ} \mathrm{C}$ is reached when the sum of the stem section at $1 \mathrm{~m} 30(G)$ reaches $20 \mathrm{~m}^{2} \mathrm{ha}^{-1}$ (i.e. $0.2 \%$ of the total surface).

2. The foliage modifies convection: the maximum coverage is the sum of the vertical projection of each tree canopy. This value is modified depending on the leaf area already developed for a given year. The relationship is considered linear between 0 (bud-break) and $A_{\mathrm{x}}$ (full leaf development). It is assumed that with an $80 \%$ coverage, the increase in temperature reaches $2^{\circ} \mathrm{C}$ and that before this value the relationship is linear.

1.2.4.3. Wind speed. Wind speed is modified in two ways: a horizontal decrease of the wind speed and a vertical increase of the eddies (Green, 1991; Green et al., 1995). Based on Green's data, the empirical relationship has been drawn:

$C(t)=C_{0}(t) \cdot \mathrm{e}^{-0.1852 \cdot G\left(t_{\mathrm{y}}\right)}$

where $C_{0}(t)$ is the wind-speed without trees; $G\left(t_{\mathrm{y}}\right)$ is the sum of the stem section at $1 \mathrm{~m} 30$.

1.2.4.4. Rainfall. Rainfall is partly intercepted by the trees depending on the leaf area on the plot (Aston, 1979; Teklehaimanot and Jarvis, 1991):

$R(t)=R_{0}(t)-\left[0.073 \cdot A_{\mathrm{t}}(t)\right]$

where $R_{0}(t)$ is the rainfall without trees on the plot; $A_{\mathrm{t}}(t)$ is the sum of the tree leaf area on the plot.

1.2.4.5. PET. As the radiation and the air temperature are modified, the PET on the plot is modified and calculated by using the PenmanMonteith equation (Monteith and Unsworth, 1990).

\subsubsection{Sharing radiation}

The tree receives the total amount of radiation. Its canopy decreases the amount reaching the sward as described in Eq. (8). This is this amount of radiation which is used in sward growth process Eq. (4). The larger the tree is, the less radiation reaches the sward (Bergez et al., 1997b).

\subsubsection{Sharing water}

Following Lecomte and Dupraz (1996), the soil is divided into two layers (superficial and deep; only trees have access to the deep layer) and into three zones (weeded and influenced by the tree, unweeded and influenced by the tree, not influenced by the tree). Within the weeded area, soil and tree compete to extract the water and within the unweeded area, tree competes with sward. Coefficients are used to describe the competition between tree, soil and sward and the ratio between the water taken up from the shallow and the deep layer of the soil for the tree. Potential transpiration for the tree $\left(E_{\mathrm{t}}\right)$ and for the sward $\left(E_{\mathrm{s}}\right)$ and soil evaporation $\left(E_{\mathrm{g}}\right)$ are calculated as follows:

$$
\begin{aligned}
& E_{\mathrm{t}}(t)=A_{\mathrm{t}}(t) \cdot E_{\mathrm{t}, \mathrm{x}} \cdot \operatorname{PET}(t) / \operatorname{PET}_{\mathrm{t}, \mathrm{x}} \\
& E_{\mathrm{g}}(t)=A_{g}\left(t_{\mathrm{y}}\right) \cdot E_{\mathrm{g}, \mathrm{x}} \cdot \operatorname{PET}(t) / \operatorname{PET}_{\mathrm{g}, \mathrm{x}} \\
& E_{\mathrm{s}}(t)=f \operatorname{ETM} \cdot \operatorname{PET}(t) \cdot A_{\mathrm{S}}(t) / A_{\mathrm{S}, 0}
\end{aligned}
$$

where $A_{\mathrm{t}}(t)$ is the tree leaf area; $E_{\mathrm{t}, \mathrm{x}}$ is the maximum transpiration obtained at $\operatorname{PET}_{\mathrm{t}, \mathrm{x}} ; A_{\mathrm{g}}\left(t_{\mathrm{y}}\right)$ is the bare soil area; $E_{\mathrm{g}, \mathrm{x}}$ is the maximum soil evaporation obtained at $\mathrm{PET}_{\mathrm{g}, \mathrm{x}} ; f$ ETM is the coefficient equal to potential evapo-transpiration/ maximum evapo-transpiration at $A_{\mathrm{s}, 0}$ (referenced leaf area index); $A_{\mathrm{s}}(t)$ is the sward leaf area index.

\subsubsection{Sharing nitrogen}

There is no competition between the sward and the tree to share the mineral nitrogen pool of the soil because it is assumed that the tree uptakes its nitrogen requirements from the deep soil layer. Tree growth is not nitrogen dependant and furthermore, its leaf litter is returned to the soil at fall, allowing nitrogen recycling. Sward senescence material, tree leaves litter and faeces are returned to the mineral nitrogen pool to the soil (Thornley and Verberne, 1989). 


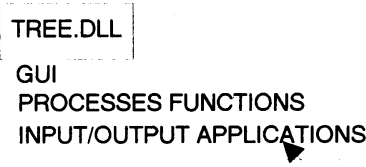

Water stress coefficient

[Pruning, Thinning, Felling]

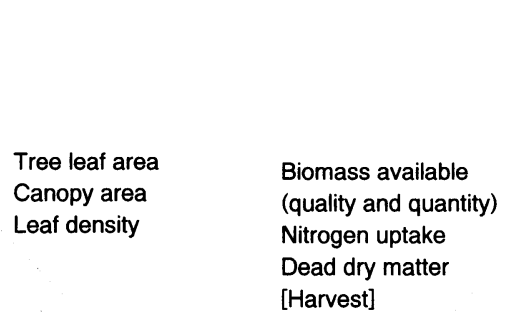

SWARD.DLL

GUI PROCESSES FUNCTIONS INPUT/OUTPUT APPLICATIONS

Biomass grazed Nitrogen available

Water stress coefficient

Microclimate

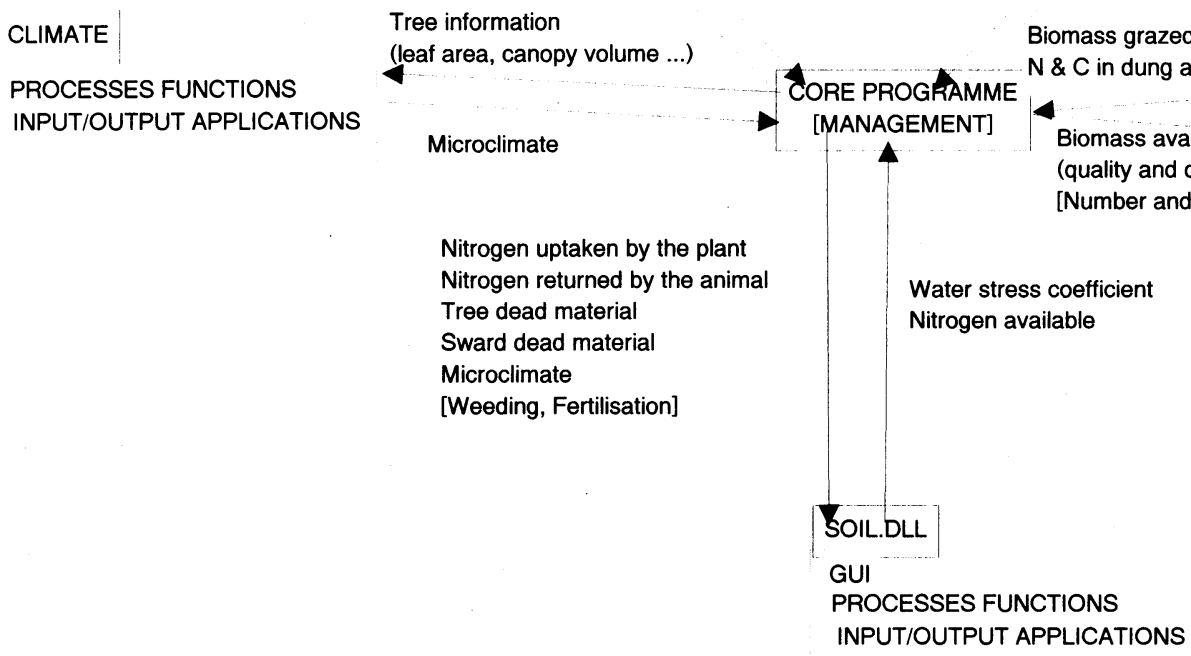

Fig. 2. Objects relationships diagram. Each object, coded in a separate DLL, exchanges information (a) through a particular graphic user interface (GUI); (b) through the main core programme; and (c) by exporting ASCII files. We added on the graph the management practices [ ] which are information used by the different methods of the objects.

\subsection{Description of the relationships between the objects of the model}

\subsubsection{Static aspects}

The relationships between the different objects describe the interactions between the components of a silvopastoral system. They are based on exchange of information between the different objects through the main core programme (Fig. 2).

The first level of exchange of information is through the 'graphic user interfaces', allowing the user to directly parametrize the model, or through reading ASCII file input. All the objects, except the climate, have a dialogue box allowing a description of the initial state of the object and parametrisation of the growth processes and budget methods (Fig. 3A). The climate object is initialised through an ASCII file.
The second level of exchange of information is through the main core programme which distributes information from one object to the other objects to deal with the interactions. Management practices are part of this information (Fig. 3B). Decision rules may therefore be chosen to perform any particular action (e.g. fertilising the plot, thinning the stand, withdrawing the flock from the plot) and knowledge is then given to the object to perform the action.

The third level of exchange of information is the outputs from the different objects to ASCII files to allow the user to keep track of the evolution of the objects. This level is a useful one as far as decision support systems (DSS) are concerned.

\subsubsection{Dynamic aspects}

The spatial disaggregation scale in ALWAYS 


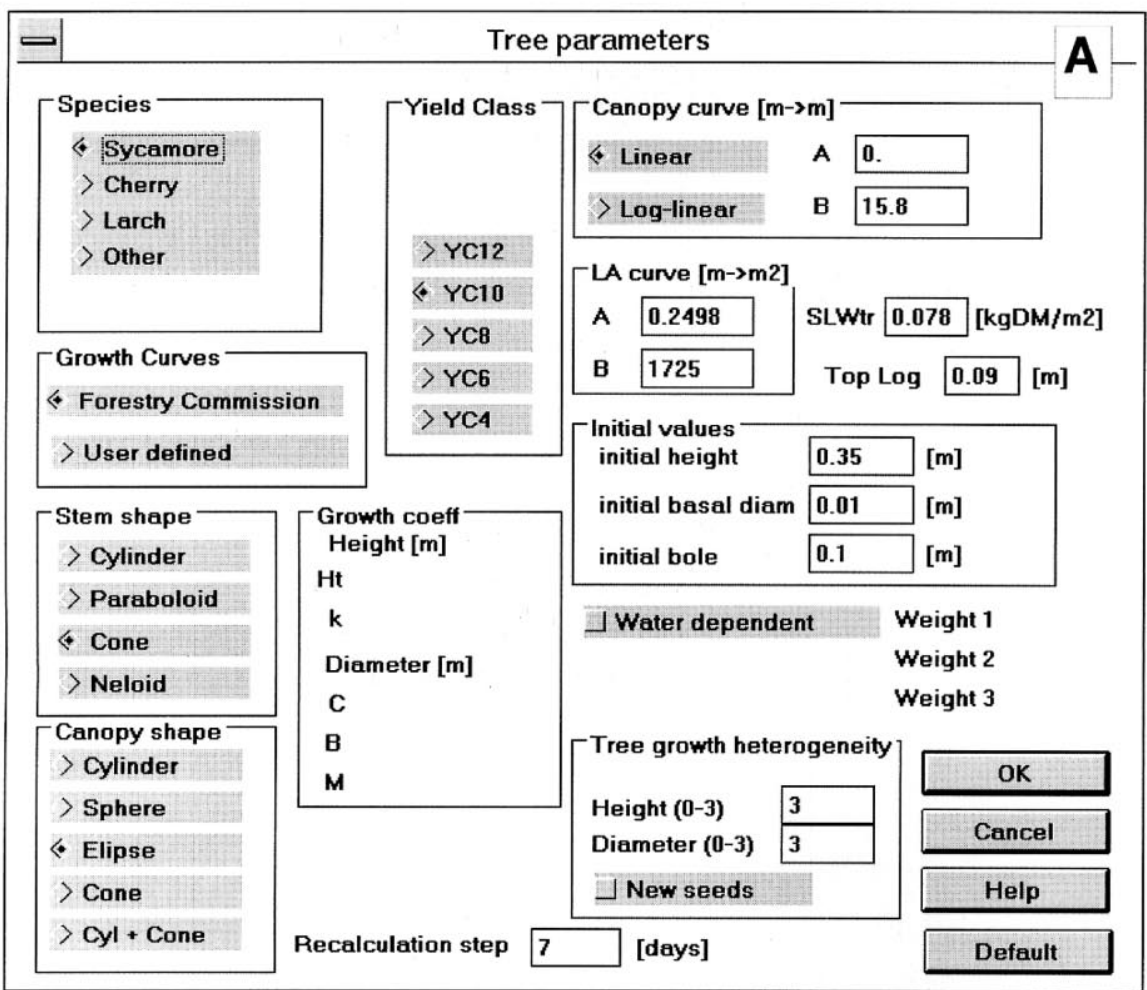

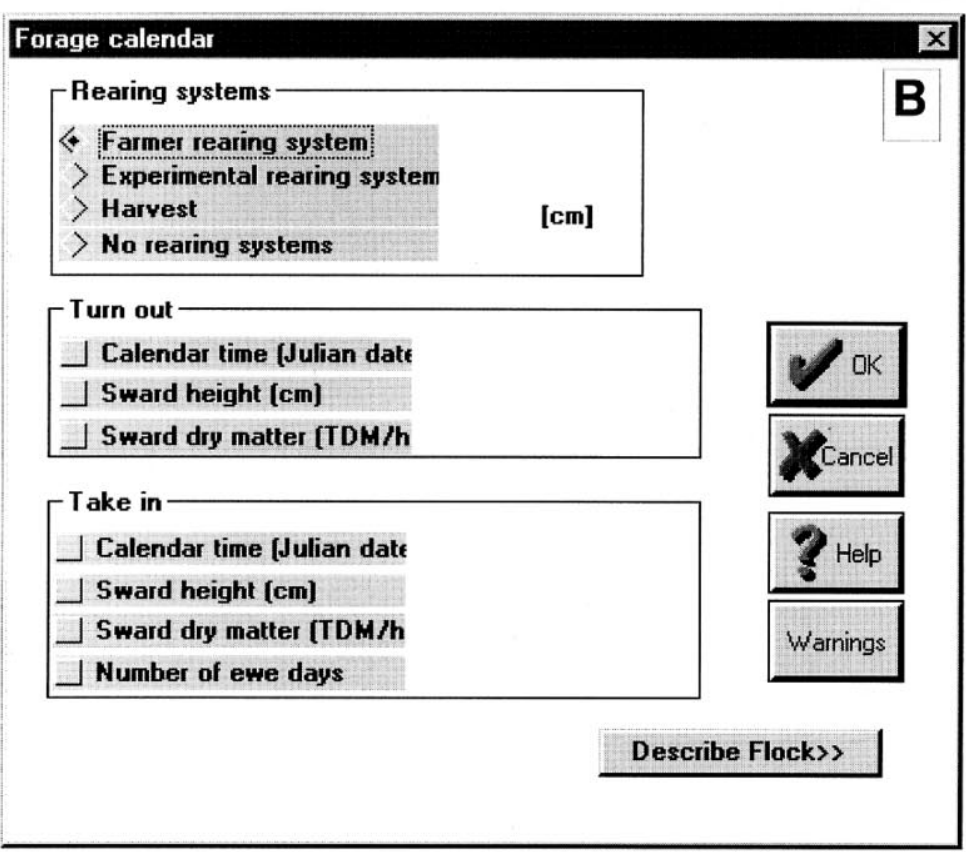

Fig. 3. (A) An example of graphic user interface to initialise the tree object. The user may enter his own parameters or use the default button which provides data form a UK site. Data are checked for consistency before the model runs. (B) The rearing system window allows to describe how to manage the sward production: hay cutting; animal grazing. 

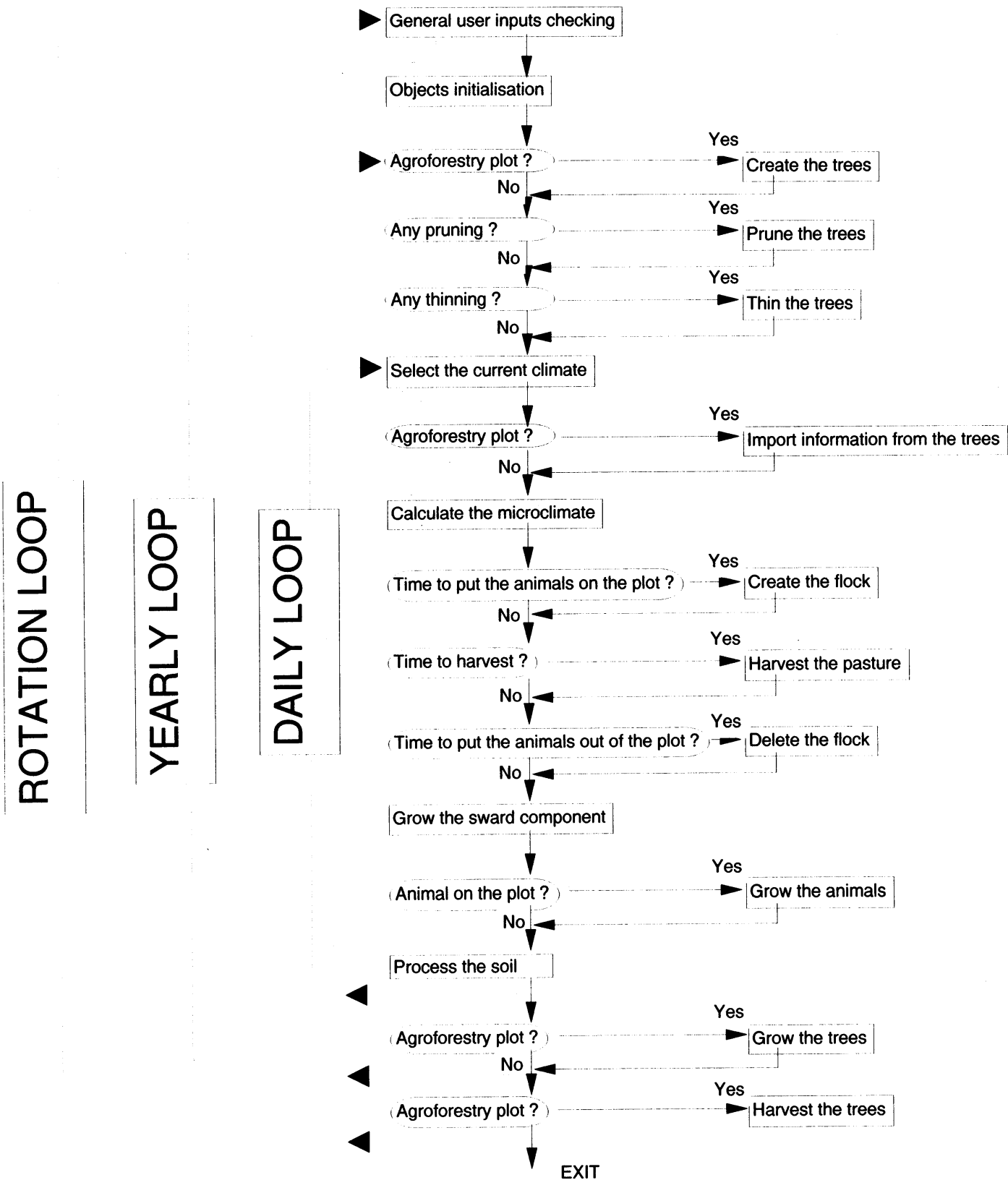

Fig. 4. Objects dynamic in ALWAYS model.

is the plot unit when dealing with animal, soil, sward and climate processes, but the individual tree where tree processes are concerned. Average values are given on a plot basis (e.g. mean microclimate, mean water budget).
Processes are carried out on a daily basis except for the tree growth which is annual. However, tree leaf area development is dealt with on a daily basis to allow calculation of the micro-climate on a daily basis. 
Fig. 4 shows the dynamics of the objects within the three temporal loops; daily, yearly and rotational. This procedural chart shows that each day the micro-climate is computed first, then the rearing system is taken into account if required, then the sward is processed, then the animal and finally the soil. At the end of the year, the trees grow.

\subsubsection{Programming aspects}

The model has been developed using the objectoriented programming language $\mathrm{C}++$ (Stroustrup, 1993) using the Object Windows Libraries marketed by Borland ${ }^{\mathrm{TM}}$ (Borland International, 1994). Each object has been coded as an independent dynamic library. This allows great flexibility in the use of the programme as each library may be independently modified, updated or reused.

One of the main tasks of the programming work was to allow different levels of representation depending on the end user, from a research level to more general outputs. This has been achieved by using the modularity aspect of $\mathrm{C}+$ + Windows ${ }^{\mathrm{TM}}$ programming: a core programme dealing with the initialisation and the general input/output and dynamic link libraries (DLL) for the different objects.

\subsubsection{Interfacing}

We decided to target the model to quite a wide range of users. Therefore consistent interfacing is necessary to allow different levels of complexity in the input/output processes.

- First level: the default values. Default values have been given to all the parameters. These default values represent a real system in the UK (Glensaugh site-Macaulay Land-Use Research Institute, Aberdeen). Therefore, without knowing anything about the system, it is possible to run the programme and to obtain some comprehensive outputs.

- Second level: the parameter files and the decision management tools. The user is able to modify the parameters dealing with any particular object (Fig. 3A). Year after year, the user may change the management (e.g. fertilization, weeding, pruning) after having taken a decision based on the graphs and on the results given by the programme. A file keeps track of all the management actions per- formed.

- Third level: the automatisation and sensitivity analysis. When the user is familiar with the model, it is possible to perform automatic runs to test scenarios and to test the sensitivity of some parameters. By automatic, we mean that the process will be carried out from planting to final tree harvest without any keyboard input from the user. The management and the decision rules are read from an ASCII file (e.g. thin $50 \%$ of the stand at year 15, stop applying fertiliser when tree cover is more than $40 \%$, allow four allocations for grazing and hay cutting of the plot during the year). This is a useful research and predictive tool and may be seen as a first step towards a more effective DSS tool.

\subsubsection{Types of outputs from ALWAYS}

To be useful, the model has to provide results in a way that the user may use them to analyse the management and synthesise his knowledge. Therefore, ALWAYS provides different types of outputs.

Several files are created to help the user understand the results obtained from the model and to compare simulations.

- Files holding the daily calculated variables of the objects. They are space-separated value files and can be imported under any spreadsheet package to plot graphs and perform new analyses. These files are overwritten each year, however the programme provides the possibility to save them year after year.

- A file holding the yearly results of the simulation [total sward production (TDM ha ${ }^{-1}$ year ${ }^{-1}$ ), animal offtake (TDM ha ${ }^{-1}$ year $^{-1}$ ), mean current annual increment of the trees $\left(\mathrm{m}^{3} \mathrm{ha}^{-1}\right.$ year $\left.\left.{ }^{-1}\right) \ldots\right]$. This is an ASCII comma-separated value file. This file is easily imported to any spreadsheet package and new analyses may be performed and graphs plotted. It is a useful file to analyse year on year trends of diverse management choices on the general yearly results.

- A file holding yearly results of the simulation used to assess the economic impact of the system (e.g. timber on the stand, lamb pro- 


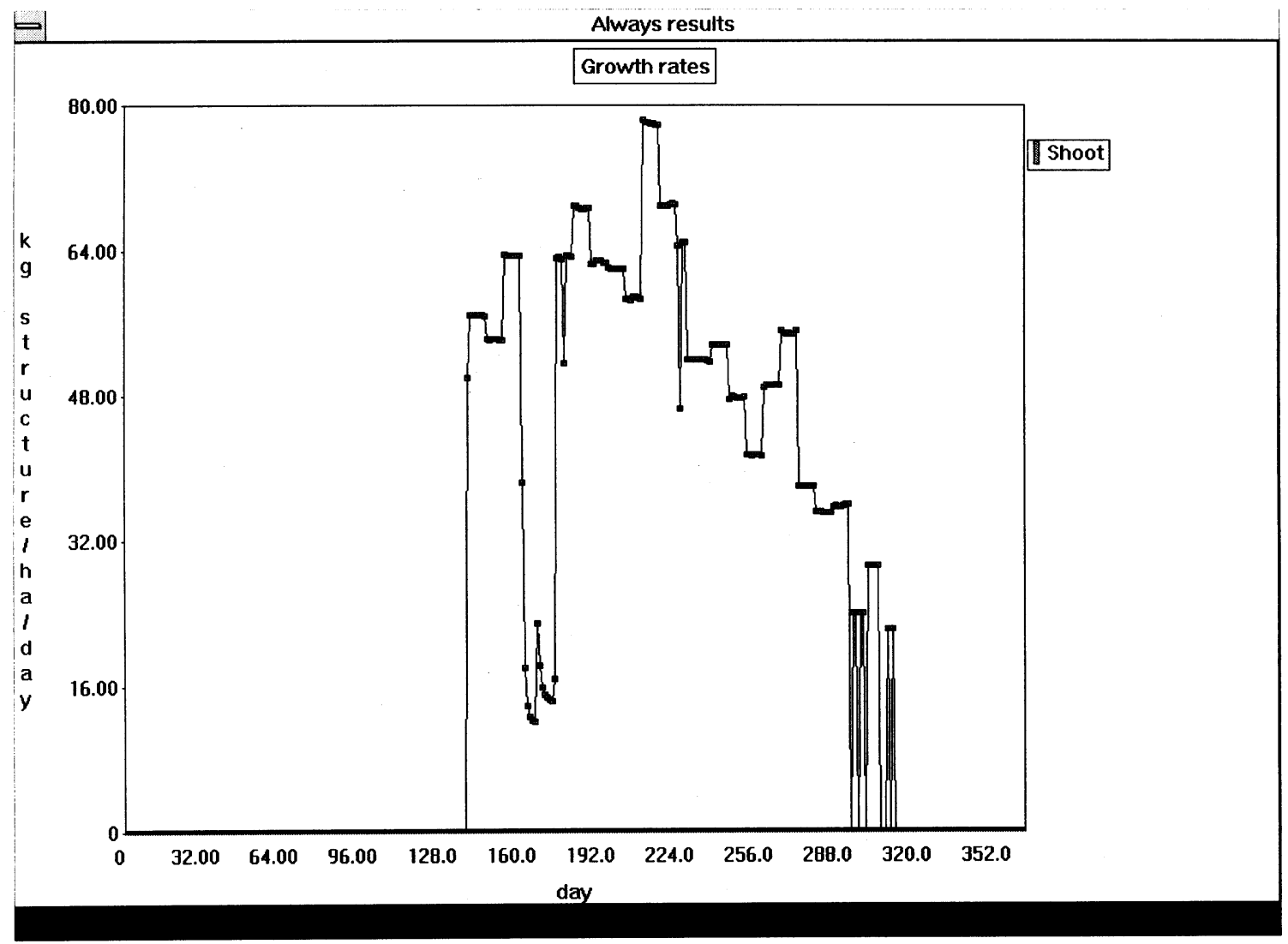

Fig. 5. An example of the graphs proposed by the model: sward growth rate.

duction, energy deficit for the animals). This is an ASCII comma-separated value file. Within the European Commission project, collaborative work was carried out to develop an economic analysis of a silvopastoral system to help understand cash flow and gross margin of such a system. This file is the link between the biophysical model and the economic spreadsheet template developed by other colleagues (Thomas, 1991; Thomas et al., 1994).

- A file recording the initial choices, the action performed during the progress of the model (e.g. fertilization, pruning, thinning) and the results year after year. This is an ASCII file with a report layout (Appendix A).

While running the model, graphs are available before each yearly run: to view the results; to check the results; to decide which new manage- ment actions are required (e.g. fertilization, pruning, thinning).

Numerous graphs are offered to the user, showing the annual trends of the properties of the different objects (for an example, see Fig. 5) and a stand representation showing the trees. This knowledge allows decisions to be made on what action to perform next depending on the objectives of the plot.

\section{Discussion}

\subsection{Calibration/validation}

The equations used to describe the biophysical processes have been developed by other scientists or have been picked up from the literature. It is therefore essential to calibrate these equations for 
a given pedo-climatic situation. In ALWAYS, only the form of the equation is mandatory, the user can change freely the parameters of a given equation to fit local conditions.

Validation of complex predictive models has always been a difficult problem but valuable tools such as simulations should not be discounted simply because of a lack of cookbook validation procedures (Brown and Kulasiri, 1996). Regarding European temperate silvopastoral systems (i.e. planted trees in pasture and not forest grazing), there is a lack of old stands to obtain valuable/ validable data. Modern silvopastoral plantations of broad-leaved trees are 10-15 years old. They may be used to validate the simulation of the early development of the system. Such a calibration and validation procedure has been successfully attempted with the ALWAYS model (Bergez et al., 1997a). A longer time is required to validate quantitatively the whole rotation. However the model can also be evaluated in a qualitative way. According to Vanclay and Skovsgaard (1997), the first step was to verify the logical organisation of the model components and the biological realism, the consistency with existing theories and to check the responses of the system to management actions. As far as the ALWAYS model is concerned, no contradictions have been pointed out in the organisation or results of the model and the simulation of management actions has, so far, given logical responses (Bergez et al., 1997a), even for contrasting livestock management practices. Secondly, the model - being a deliberate simplification - need not fit all the data available to be useful (Klepper, 1997). Lack of knowledge can be checked and additional research may be initiated to answer the questions which arise from the simulations (Le Dizès et al., 1997) or to improve the precision of some calculations.

\subsection{Limits and improvements}

During the construction phase and the early simulations, some weaknesses of ALWAYS have already been pointed out. It appeared important to increase the knowledge on some aspects.

1. The competition aspects for water between the trees and the sward roots. All the data re- quired to parametrise precisely the water competition processes are not available. In particular, data on soil exploration by the tree roots system are lacking, few studies being available on this topic (Van Noordwijk et al., 1997; De Montard et al., 1998). References on the transpiration of isolated trees are also rare because forest trees are generally studied in high density stand. The way water stress influences tree and sward growth is not entirely known. A simple formalism is used in ALWAYS to take into account the effects of water stress on tree and sward growth from the available data.

2. The evolution of the tree leaf area. The transmitted PAR under the tree is calculated using a simple vertical projection of the tree canopy. A more complex description taking into account the solar position in the sky and a three-dimensional structure of the canopy should be used. Similarly, the development of the tree leaf area, which is currently considered linear between bud-break to full development, would merit to be described more precisely. Sward production is dependent on this leaf area development through the modification of the transmitted PAR.

3. The development of isolated forest trees. Few data are available on temperate fast growing broad-leaved trees. Some research needs to be performed on this topic.

4. Finally only sheep are considered in the current version of ALWAYS. Lot of silvopastoral plots are run with cattle. A cattle version of the model should be implemented to allow larger use of the model.

\section{Conclusions}

The power of the object analysis and of the object design is very appealing when dealing with complex systems like silvopastoral systems where interaction processes are the keys to describing the performances of the whole system. ALWAYS is an example of a model of such a system, and its user-friendly structure allows it to reach a range of potential users. The use of DLLs allows easy 
modification and updating if better knowledge and understanding emerges from simulation or from new field experiments.It was decided to design the model to be used as a simple DSS tool. This DSS tool may be either governed by rules (automatic process) or by the knowledge of the user (interactive process).

The model is presently running as a test-version and is in the process of being validated in contrasting situations of temperate Europe (south and centre of France and Scotland) (Bergez et al., 1997a).

So far, ALWAYS is a plot-based model. Results from a single plot cannot be generalised to a commercial farm. Integrating the farm into a whole is a major step to reach in the near future if we want the model to better fit reality. One possibility may be to use ALWAYS as an independent model component of a more complex DSS like LADSS (Butcher et al., 1996).

\section{Acknowledgements}

The authors wish to thank Daniel Auclair, Christian Dupraz, François-Xavier de Montard (INRA, France), Alan Sibbald (MLURI, UK) and Bruno Msika (ASTER \& D, France) for their help during working on the model and writing this paper. This study was partly funded by the European Union (contract AIR3-CT 92 0124).

\section{Appendix A}

Simulation: Glensaugh: 20/1/1997-17/03/26

\section{A. INITIAL PARAMETERS}

Project file used: c: $\backslash$ jacko $\backslash$ alwmod $\backslash$ simull.PRJ Climatic file used:

$\mathrm{C}: \backslash \mathrm{JACKO} \backslash$ ALWMOD $\backslash$ DYCE.CLI

Series file used: c: $\backslash$ jacko $\backslash$ alwmod $\backslash$ simull.SER

1. Site description

Latitude (o): 56.54 , longitude (o): 2.33 , altitude $(\mathrm{m}): 175$
Slope (o): 0, aspect (o): 0

Plot: length $(\mathrm{m})=100$, width $(\mathrm{m})=100$, orientation $(\mathrm{o})=0$

2. Planting description

Planting pattern: rectangular

Distance in row $(\mathrm{m}): 6$, distance between row (m): 8

3. Soil description

Superficial layer

3.1. Texture:

sand $(\%)=62$, clay $(\%)=4$, silt $(\%)=34$, fine $(\%)=60$

depth $(\mathrm{m})=0.3$, texture $=\mathrm{SL}$

3.2. Water properties:

Hcc $(\%)=12, \operatorname{HpF}(\%)=5$, da $=1.4$ total water reserve $(\mathrm{mm})=30.24$

water quantity at wilting point $(\mathrm{mm})=12.6$

minimum soil water quantity $(\mathrm{mm})=7.56$

Deep layer

\subsection{Texture:}

sand $(\%)=62$, clay $(\%)=4$, silt

$(\%)=34$, fine $(\%)=60$

depth $(\mathrm{m})=0.6$, texture $=\mathrm{SL}$

3.2. Water properties:

Hcc $(\%)=12, \operatorname{HpF}(\%)=5, \mathrm{da}=1.4$

total water reserve $(\mathrm{mm})=60.48$

water quantity at wilting point $(\mathrm{mm})=25.2$

minimum soil water quantity $(\mathrm{mm})=15.12$

Initial values:

3.1 .

faeces: nitrogen $\left(\mathrm{kg} \mathrm{ha}^{-1}\right)=0.2$; carbon $\left(\mathrm{kg} \mathrm{ha}^{-1}\right)=50$

dead shoots: nitrogen $\left(\mathrm{kg} \mathrm{ha}{ }^{-1}\right)=$ 20; carbon $\left(\mathrm{kg} \mathrm{ha}^{-1}\right)=300$

dead roots: nitrogen $\left(\mathrm{kg} \mathrm{ha}^{-1}\right)=10$;

Carbon $\left(\mathrm{kg} \mathrm{ha}^{-1}\right)=200$

SOM: nitrogen $\left(\mathrm{kg} \mathrm{ha}{ }^{-1}\right)=8000$; carbon $\left(\mathrm{kg} \mathrm{ha}^{-1}\right)=100000$

$\mathrm{N}$ ammonia $\left(\mathrm{kg} \mathrm{N}^{-1}\right): 7.5, \mathrm{~N}$ nitrate $\left(\mathrm{kg} \mathrm{N}^{-1}\right): 2.5, \mathrm{~N}$ mineral $(\mathrm{kg}$ $\mathrm{N}$ ha $\left.{ }^{-1}\right): 10$

bug mass $\left(\mathrm{kg} \mathrm{ha}^{-1}\right): 400$

Model: water dependent; non-nitrogen dependent; non-temperature dependent 
4. Sward description

Model: empirical; water dependent; non-nitrogen dependent; non-temperature dependent

Initial values: above ground DM (kg DM ha $\left.^{-1}\right)=0$

5. Animal description

Species: sheep

Standard ewe weight $(\mathrm{kg}): 65$

Standard RAM weight (kg): 80

Standard lamb weight at weaning $(\mathrm{kg}): 25$

Standard lamb growth rate $(\mathrm{g}): 250$

Standard pregnancy length (day): 150

Standard lactation (day): 80

6. Tree description

Species: sycamore

Growth curve: Forestry Commission, yield curve: YC10

Canopy curve: linear [0., 15.8]; LAI curve: [0.2498, 1725]

Canopy shape: elipse, stem shape: cone Initial values: stem height $(\mathrm{m})=0.35$, basal diameter $(\mathrm{m})=0.01$, bole height $(\mathrm{m})=0.1$

Height variation coeff. $=3$, diameter variation coeff. $=3$

SIMULATION YEAR: 0

Climatic year $=3$

\section{MANAGEMENT}

Weeding: YES, Fertilisation: YES

\begin{tabular}{rcl}
\hline Date & Ammonium & Nitrate \\
\hline 140 & 120.0 & 0.0 \\
0 & 0.0 & 0.0 \\
0 & 0.0 & 0.0 \\
0 & 0.0 & 0.0 \\
0 & 0.0 & 0.0 \\
\hline
\end{tabular}

\section{FORAGE CALENDAR}

Initial choices:

Type of forage calendar: HARVEST
Plot harvested (Julian date: 1), quantity harvested $\left(\mathrm{T} \mathrm{ha}^{-1}\right)$ : 0

Initial choices:

Type of forage calendar: FARMER

Put out: resource $\mathrm{DM}=1.5$

Put in: resource $\mathrm{DM}=0.6$

Flock description: 50 single lactating ewes, 40 days from birth

Animals put on the plot on: 147 (Julian date) Animals removed from the plot on: $178(\mathrm{Ju}-$ lian date)

Initial choices:

Type of forage calendar: HARVEST

Plot harvested (Julian date: 206), quantity harvested $\left(\mathrm{T} \mathrm{ha}^{-1}\right)$ : 1.10457

Initial choices:

Type of forage calendar: FARMER

Put out: resource $\mathrm{DM}=1$

Put in: date $=365$, resource $\mathrm{DM}=0.3$

Flock description: 50 dry ewes, -365 days before mating

Animals put on the plot on: 223 (Julian date) Animals removed from the plot on: $231(\mathrm{Ju}-$ lian date)

Initial choices:

Type of forage calendar: NONE

\section{RESULTS}

1. Climate

Radiation (\% control): 99.9736, Rain (\% control): 99.9919 , PET (\% control) 99.9726

2. Sward

Total aboveground production $\left(\mathrm{T} \mathrm{ha}{ }^{-1}\right)$ : 9.49329

Harvest production $\left(\mathrm{T} \mathrm{ha}^{-1}\right): 1.10457$

Total animal offtake ( $\mathrm{T}$ ha $\left.{ }^{-1}\right): 5.23663$

Total nitrogen uptake $\left(\mathrm{kg} \mathrm{ha}^{-1}\right)$ : 0

3. Soil

$\mathrm{N}$ still available $\left(\mathrm{kg} \mathrm{ha}^{-1}\right): 10$

$\mathrm{N}$ leached $\left(\mathrm{kg} \mathrm{ha}^{-1}\right)$ :

$\mathrm{Nb}$ of day with sward experiencing water deficit: 19

\section{Animal}

Carrying capacity ( $\mathrm{T}$ days $\mathrm{ha}^{-1}$ ): 155.425

Lamb production $\left(\mathrm{kg} \mathrm{ha}^{-1}\right): 260.817$

Total MS grazing deficit (TDM ha ${ }^{-1}$ ): 0.0446234 
Total ME grazing deficit (GJ ha ${ }^{-1}$ ): 0.655074 ( -0.949383 UF)

Total $\mathrm{N}$ returned to the soil $\left(\mathrm{kg} \mathrm{N} \mathrm{ha}^{-1}\right)$ : 241.771

5. Tree [variance]

Survival (nb tree/plot): 192

Stand mean height $(\mathrm{m}): 1.31792$ [0.0462178]

Stand mean DBH (m): 0.00265245

[1.46428e-05]

Stand mean bole (m): $0.1[0]$

Volume $\left(\mathrm{m}^{3}\right.$ plot $\left.^{-1}\right): 0.101381$, CAI $\left(\mathrm{m}^{3}\right.$

ha $^{-1}$ year $\left.^{-1}\right)$ : 0.0961031, MAI $\left(\mathrm{m}^{3}\right.$

ha -1 year $\left.{ }^{-1}\right)$ : 0

Cover (\%): 0.211341, growth reduction factor: 0

SIMULATION YEAR: 1

Climatic year $=2$

1. MANAGEMENT

Weeding: YES, Fertilisation: YES

\begin{tabular}{rcl}
\hline Date & Ammonium & Nitrate \\
\hline 140 & 120.0 & 0.0 \\
0 & 0.0 & 0.0 \\
0 & 0.0 & 0.0 \\
0 & 0.0 & 0.0 \\
0 & 0.0 & 0.0 \\
\hline
\end{tabular}

(OTHER YEARS)

SIMULATION YEAR: 62

Climatic year $=4$

\section{MANAGEMENT}

Weeding: NO, Fertilisation: YES

\begin{tabular}{lll}
\hline Date & Ammonium & Nitrate \\
\hline 140 & 120.0 & 0.0
\end{tabular}

$\begin{array}{lll}0 & 0.0 & 0.0 \\ 0 & 0.0 & 0.0 \\ 0 & 0.0 & 0.0 \\ 0 & 0.0 & 0.0\end{array}$

\section{FORAGE CALENDAR}

Initial choices:

Type of forage calendar: HARVEST

Plot harvested (Julian date: 1), quantity harvested $\left(\mathrm{T} \mathrm{ha}^{-1}\right): 0.574095$

Initial choices:

Type of forage calendar: FARMER

Put out:, resource $\mathrm{DM}=1.5$

Put in:, resource $\mathrm{DM}=0.6$

Flock description: single lactating ewes, 40 days from birth

Animals put on the plot on:149 (Julian date)

Animals removed from the plot on:171 (Julian date)

Initial choices:

Type of forage calendar: HARVEST

Plot harvested (Julian date: 212), quantity harvested $\left(\mathrm{T} \mathrm{ha}^{-1}\right)$ : 1.08427

Initial choices:

Type of forage calendar: FARMER

Put out:, resource $\mathrm{DM}=1$

Put in: date $=365$, resource $\mathrm{DM}=0.3$

Flock description: dry ewes, -365 days before mating

Animals put on the plot on: 247 (Julian date)

Animals removed from the plot on: $254(\mathrm{Ju}-$ lian date)

Initial choices:

Type of forage calendar: NONE

\section{RESULTS}

1. Climate

Radiation (\% control): 86.4083 , rain ( $\%$ control): 98.461, PET (\% control) 85.5138

2. Sward

Total aboveground production $\left(\mathrm{T} \mathrm{ha}^{-1}\right)$ : 7.66611 
Harvest production $\left(\mathrm{T} \mathrm{ha}^{-1}\right): 1.65836$

Total animal offtake ( $\left.\mathrm{T} \mathrm{ha}{ }^{-1}\right): 3.86719$

Total nitrogen uptake $\left(\mathrm{kg} \mathrm{ha}^{-1}\right)$ : 0

3. Soil

$\mathrm{N}$ still available $\left(\mathrm{kg} \mathrm{ha}^{-1}\right): 10$

$\mathrm{N}$ leached $\left(\mathrm{kg} \mathrm{ha}^{-1}\right)$ :

$\mathrm{Nb}$ of day with sward experiencing water deficit: 23

\section{Animal}

Carrying capacity ( $\mathrm{T}$ days $\left.\mathrm{ha}^{-1}\right): 113.363$

Lamb production $\left(\mathrm{kg} \mathrm{ha}^{-1}\right): 185.096$

Total MS grazing deficit (TDM ha ${ }^{-1}$ ): 0.0598979

Total ME grazing deficit (GJ ha ${ }^{-1}$ ): $0.782176(-1.13359$ UF $)$

Total $\mathrm{N}$ returned to the soil $\left(\mathrm{kg} \mathrm{N}^{\mathrm{N}} \mathrm{a}^{-1}\right)$ : 187.241

5. Tree [variance]

Survival (nb tree plot $^{-1}$ ): 77

Stand mean height (m): 20.3651 [2.18822]

Stand mean DBH (m): 0.400119 [0.002953]

Stand mean bole $(\mathrm{m}): 6$ [0]

Volume $\left(\mathrm{m}^{3}\right.$ plot $\left.^{-1}\right)$ : 76.4077, CAI $\left(\mathrm{m}^{3}\right.$ $\mathrm{ha}^{-1}$ year $\left.{ }^{-1}\right)$ : 1.89809, MAI $\left(\mathrm{m}^{3} \mathrm{ha}^{-1}\right.$ year $^{-1}$ ): 1.23238

Cover (\%): 20.7551, growth reduction factor: 0.52681

TIMBER PERFORMED

Number of trees timbered: 77

Volume timbered $\left(\mathrm{m}^{3}\right)$ : 93.476

Mean volume removed $\left(\mathrm{m}^{3}\right.$ tree $\left.{ }^{-1}\right): 1.21397$

Bottom log volume $\left(\mathrm{m}^{3}\right)$ : 59.0719, top log volume $\left(\mathrm{m}^{3}\right): 34.3903$, fire wood volume $\left(\mathrm{m}^{3}\right): 0.0137867$

Simulation ended: 17:06:19

\section{References}

Acock, B., Reynolds, J.F., 1997. Introduction: modularity in plant models. Ecol. Model. 94, 1-6.

Acock, B., Reddy, V.R., 1997. Designing an object-oriented structure for crop models. Ecol. Model. 94, 33-44.

Anderson, L.S., Sinclair, F.L., 1993. Ecological interactions in agroforestry systems. Agrofor. Abs. 6, 57-91.

Aston, A.R., 1979. Rainfall interception by eight small trees. J. Hydrol. 42, 383-396.
Auclair, D., 1996. Scientific and technical basis for silvopastoral systems in Europe. In: Etienne, M. (Ed.), Western European Silvopastoral Systems. INRA Editions, Paris, France, pp. 195-206.

Bergez, J.-É., Étienne, M., Balandier, P., 1997a. Sensitivity analysis of the ALWAYS silvopastoral simulation model across contesting pedoclimatic conditions. In: INRACIRAD (Ed.) Agroforestry for sustainable land use. International workshop, 23-29 June 1997, Montpellier, France, pp. 391-394.

Bergez, J.-É., Dalziel, A.J.I., Duller, C., Eason, W.R., Hoppe, G., Lavender, R.H., 1997b. Light modification in a developing silvopastoral system in the UK: a quantitative analysis. Agrofor. Syst. 37 (3), 227-240.

Bergez, J.-É, Msika, B., 1996. A silvopastoral model for the EU. In: Etienne, M. (Ed.), Western European Silvopastoral Systems. INRA Editions, Paris, France, pp. 207-220.

Booch, G., 1994. Object-Oriented Analysis and Design with Applications. Benjamin/Cummings, Redwood City, CA, p. 589.

Borland International, 1994. ObjectWindows, Reference Guide Version 2.5. Scotts Valley, CA.

Brown, T.N., Kulasiri, D., 1996. Validating models of complex, stochastic, biological systems. Ecol. Model. 86, 129134.

Butcher, C.S., Matthews, K.B., Sibbald, A.R., 7-11 July 1996. The implementation of a spatial land allocation decision support system for upland farms in Scotland. In: M.K. van Ittersum, G.E.G.T. Venner, S.C. van de Geijn T.H. Jetten (Eds.), Proceedings of the European Society for Agronomy Fourth Congress. Veldhoven/Wageningen, The Netherlands, pp. 416-417.

Cabanettes, A., Auclair, D., Imam W., 1998. Diameter and height growth curves for widely spaced trees in European agroforestry. Agrofor. Syst. (special issue) (in press).

Coppel, B., Étienne, M., 1992. Modélisation de la production fourragère dans une vallée des Préalpes: application à la mise à l'herbe en exploitation. Fourrages 132, 365-380.

De Montard, F.-X., 1986. Calcul simplifié du potentiel de production et des exportations d'azote dans les prairies. Les Colloques de l'INRA 39, 367-389.

De Montard, F.X., Rayeg, H., Delpy, R., Massey, P., 1998. Competition for light, water and nitrogen in an association of hazel and cockfoot. Agrofor. Syst. (special issue) (in press).

De Reffye, P., Houllier, E., Blaise, F., Barthélémy, D., Dauzat, J., Auclair, D., 1995. A model simulating aboveand below-ground tree architecture with agroforestry applications. Agrofor. Syst. 30, 175-197.

Doyle, C.J., Evans, J., Rossiter, J., 1986. Agroforestry: an economic appraisal of the benefits of inter-cropping trees with grassland in lowland Britain. Agric. Syst. 21, 1-32.

Étienne, M, 1996. Research on temperate and tropical silvopastoral systems: a review. In: Etienne, M. (Ed.), Western European Silvopastoral Systems. INRA Editions, Paris, France, pp. 5-19.

Forestry Commission, 1980. Yield models for forest management. Alice Holt Lodge. 
Garcia-de-Ceca, J., Gebremedhin, K., 1991. A decision support system for planning agroforestry systems. For. Ecol. Manag. 45, 199-206.

Giordano, E., Leone, A., Ragno, D., Schirone, B., 1986. Studio dell'ombra proiettata durante l'anno dalla chioma di un albero. Italia Forestale e Montana 86, 129-150.

González, I., 1984. Balance energético en la explotación de pastizales forestales, aplicación a un caso concreto. Comunicaciones INIA, serie Recursos Naturales, pp. 45.

Green, S.R., 1991. Air flow through and above a forest of widely spaced trees, $\mathrm{PhD}$ thesis. University of Edinburgh, UK, pp. 313.

Green, S.R., Grace, J., Hutchings, N.J., 1995. Observations of turbulent air flow in three stands of widely spaced Sitka spruce. Agric. For. Meteorol. 74, 205-225.

Guitton, J.L., 1994. L'agroforesterie? Rev. For. Fr. 46, 11-16.

Guitton, J.L., Dupraz, C., Auclair, D., De Montard, F.-X., 1994. Quel projet agroforestier pour l'Europe tempérée? Rev. For. Fr. 46, 179-187.

Jackson, J.E., Palmer, J.W., 1979. A simple model of light transmission and interception by discontinuous canopies. Ann. Bot. 44, 381-383.

Klepper, O., 1997. Multivariate aspects of model uncertainty analysis: tools for sensitivity analysis and calibration. Ecol. Model. 101, 1-13.

Khan, T., Pathak, P., 1995. Modelling silvopastoral systems in dry rangelands. Cahiers Options Méditerranéennes 12, 235-238.

Kuuluvainen, T., Pukkala, T., 1989. Simulation of within-tree and between-tree shading of direct radiation in a forest canopy: effect of crown shape and sun elevation. Ecol. Model. 49, 89-100.

Lecomte, I., Dupraz, C., 1996. Modélisation du partage de l'eau entre un arbre et une culture intercalaire, Internal report. INRA-Montpellier, France, pp. 80.

Le Dizès, S., Cruiziat, P., Lacointe, A., et al., 1997. A model for simulating structure-function relationships in walnut tree growth processes. Silva Fennica 31 (3), 313-328.

Lilieholm, R., Reeves, L., 1991. Incorporating economic risk aversion in agroforestry planning. Agrofor. Syst. 13, 6371.

Maxwell, T.J., Sibbald, A.R., Eadie, J., 1979. Integration of forestry and agriculture-a model. Agric. Syst. 4, 161188.

McKeon, G., Day, K., Howden, S., et al., 1990. Northern Australian savannas: management for pastoral production. J. Biogeogr. 17, 355-372.

McMurtrie, R., Wolf, L., 1983. A model of competition between trees and grass for radiation, water and nutrients. Ann. Bot. 52, 449-458.

Mitchell, J., Bartling, P., 1991. Comparison of linear and non-linear overstorey-understorey models for ponderosa pine. For. Ecol. Manag. 42, 195-204.
Monteith, J.L., Unsworth, M.H., 1990. Principles of Environmental Physics. E. Arnold, London, p. 263.

Msika B., 1993. Modélisation des relations herbe-arbre sous peuplements de Quercus pubescens Willd. et Pinus austriaca Höss. dans les préalpes du Sud, PhD. University Aix-Marseille III, France, pp. 111.

Muetzelfeldt, R., Sinclair, F., 1993. Ecological modelling of agroforestry systems. Agrofor. Abs. 6, 207-247.

Oldeman, R., 1992. Architectural models, fractals and agroforestry design. Agric. Ecosyst. Env. 41, 179-188.

Reid, R., Ferguson, I., 1992. Development and validation of a simple approach to modelling tree shading in agroforestry systems. Agrofor. Syst. 20, 243-252.

Scanlan, J., 1992. A model of woody-herbaceous biomass relationships in eucalypt and mesquite communities. J. Range Manag. 45, 75-80.

Sequiera, R.A., Sharpe, P.J.H., Stone, N.D., El-Zik, K.M., Makela, M.E., 1991. Object-oriented simulation: plant growth and discrete organ to organ interactions. Ecol. Model. 58, 55-89.

Sequiera, R.A., Olson, R.L., McKinion, J.M., 1997. Implementing generic, object-oriented models in biology. Ecol. Model. 94, 17-31.

Sibbald, A.R., 1996. Silvopastoral systems on temperate sown pastures: a personal perspective. In: Etienne, M. (Ed.), Western European Silvopastoral Systems. INRA Editions, Paris, France, pp. 23-36.

Sibbald, A.R., Griffiths, J.H., Elston, D.A., 1990. The effects of the presence of widely spaced conifers on under-storey herbage production in the UK. For. Ecol. Manag. 45, $71-77$.

Silvert, W., 1993. Object-oriented ecosystem modelling. Ecol. Model. 68, 91-118.

Stroustrup, B., 1993. The $\mathrm{C}++$ Programming Language. Addison-Wesley, Reading, MA, p. 685.

Teklehaimanot, Z., Jarvis, P.G., 1991. Modelling of rainfall interception loss in agroforestry. Agrofor. Syst. 14, 65-80.

Thomas, T.H., 1991. A spreadsheet approach to the evaluation of the economics of temperate agroforestry. For. Ecol. Manag. 45, 207-235.

Thomas, T.H., Willis, R.W., Winterbourne, J., Samuel, J.H., 1994. Bio-economic agroforestry modelling: the BEAM project. Agrofor. Forum 5 (2), 65-72.

Thornley, J.M.H., Verberne, E.L.J., 1989. A model of nitrogen flows in grassland. Plant Cell Environ. 12, 863-886.

Uresk, D., Sevenson, K., 1989. Understorey-overstorey relationships in ponderosa pine forests. J. Range Manag. 42, 203-208.

Vanclay, J.L., Skovsgaard, J.P., 1997. Evaluating forest growth models. Ecol. Model. 98, 1-12.

Van Noordwijk, M., Ong, C., Buresh, R., 1997. Current root research issues at ICRAF. Agrofor. Forum 7 (2), 12-18. 